\title{
Pengembangan Perangkat Pembelajaran Pada Mata Kuliah Sejarah Indonesia Dengan Menggunakan Pendekatan CTL
}

\author{
Refinaldi, Ahmad Nurhuda
}

\begin{abstract}
Abstrak
Salah satu mata kuliah pendidikan sejarah yang diberikan kepada mahasiswaProgram Studi Tadris IPS Sejarahadalah Mata Kuliah Sejarah Indonesia Zaman Hindu - Budha. Dimana mata kuliah ini terdiri dari 2 SKS yang wajib diambil oleh mahasiswa pada semester III. Mata Kuliah Sejarah Indonesia Zaman Hindu - Budhaini adalah mata kuliah wajib di Program Studi Tadris IPS Sejarah. Sehingga mahasiswa perlu lebih menguasai dan memahami mata kuliah ini seoptimal mungkin. Untuk itu perlu dicarikan pendekatan pembelajaran yang tepat pada mata kuliah ini mata kuliah Sejarah Indonesia Zaman Hindu - Budha. Mahasiswa 100\% setuju jika dalam penyajian buku ajar digunakan metode pembelajaran. Mahasiswa $94 \%$ setuju pada buku ajar Sejarah Indonesia Zaman Hindu - Budha perlu dimasukan contoh-contoh soal. Mahasiswa 98\% setuju bahwa perlu disertakan glosarium dalam buku ajar.Mahasiswa 82\% berharap agar bahan ajar sejarah dikemas dalam bentuk buku ajar. Mahasiswa $92 \%$ setuju agar dalam menulis buku Sejarah Indonesia Zaman Hindu - Budhamenggunakan huruf/ jenis huruf (font) time new roman. Mahasiswa 100\% setuju agar dalam menulis buku Sejarah Indonesia Zaman Hindu - Budha dibuatkan daftar pustakanya dan Mahasiswa 100\% setuju agar buku yang akan ditulis itu diberi judul: Sejarah Indonesia Zaman Hindu - Budha
\end{abstract}

Kata Kunci: Pengembangan, Perangkat pembelajaran, mata kuliah sejarah Indonesia, pendekatan CTL

\section{Pendahuluan}

Salah satu mata kuliah pendidikan sejarah yang diberikan kepada mahasiswaProgram Studi Tadris IPS Sejarahadalah Mata Kuliah Sejarah Indonesia Zaman Hindu - Budha. Dimana mata kuliah ini terdiri dari 2 SKS yang wajib diambil oleh mahasiswa pada semester III. Mata Kuliah Sejarah Indonesia Zaman Hindu - Budhaini adalah mata kuliah wajib di Program Studi Tadris IPS Sejarah. Sehingga mahasiswa perlu lebih menguasai dan memahami mata kuliah ini seoptimal mungkin. Untuk itu perlu dicarikan pendekatan pembelajaran yang tepat pada mata kuliah ini.Menurutpeneliti, pendekatan yang sesuai adalah pendekatan Contextual Teaching and Learning(CTL).

Pendekatan CTL (Contextual Teaching and Learning) merupakan salah satu pendekatan yang diduga akan bisa mengatasi permasalahan pembelajaran pada mata kuliahSejarah Indonesia Zaman Hindu - Budha. Pemilihan pendekatan yang menarik dapat memicu mahasiswa untuk ikut 
serta secara aktif dalam proses pembelajaran. Mahasiswa akan belajar lebih baik jika lingkungan belajar diciptakan lebih alamiah. Belajar akan lebih bermakna jika mahasiswa melakukan sendiri apa yang dipelajarinya, tidak hanya "mengetahui" saja. Pembelajaran dengan pendekatan CTL (Contextual Teaching and Learning) merupakan konsep belajar yang membantu dosen mengaitkan antara materi yang diajarkannya dengan situasi nyata mahasiswa dan mendorong mahasiswa membuat hubungan antara pengetahuan yang dimilikinya dengan penerapannya dalam kehidupan meraka sebagai anggota keluarga dan masyarakat. Dengan pendekatan ini pembelajaran Sejarah Indonesia Zaman Hindu - Budha dapat dikaitkan dengan keadaan di sekitarnya, situasi yang sering dialami mahasiswa dalam kehidupan sehari-hari.Dalam CTLyang menjadi pusat kegiatan adalah mahasiswa, bukan dosen. Mahasiswa membangun pengetahuan mereka sendiri setelah mereka mempelajari materi yang akan dipaparkan.

Berdasarkan pengamatan di dalam kelas yang peneliti lakukan terhadap mahasiswa Prodi Tadris IPS SejarahFakultas Tarbiyah dan Keguruan UIN Imam Bonjol Padang, Khususnya pada Mata Kuliah Sejarah IndonesiaZaman Hindu - Budha, mahasiswa banyak mengalami kendala dalam proses pembelajaran dilihat dari bahan ajar dan media yang terbatas. Bagi peneliti sendiri sebagai dosen pengampu mata kuliah Sejarah Indonesia Zaman Hindu - Budha ini juga mengalami kesulitan dalam membuat perangkat pembelajaran yang sesuai dengan mata kuliah ini. Untuk itu peneliti akan melakukan penelitian tentang pengembangan perangkat pembelajaran melalui pendekatan CTL, diharapkan menjadikan mahasiswa lebih aktif dan mampu merancang kegiatan dan menemukan konsep bukan dari hasil mengingat konsep yang diberikan oleh dosen. Pengembangan ini diwujudkan dalam sebuah penelitian yang berjudul "Pengembangan Perangkat Pembelajaran Pada Mata Kuliah Sejarah Indonesia Dengan Menggunakan PendekatanCTL (Contextual Teaching and Learning)".

\section{Hasil Penelitian}

Pengembangan Perangkat Pembelajaran Pada Mata Kuliah Sejarah Indonesia dengan Menggunakan PendekatanCTL (Contextual Teaching and Learning), menggunakan beberapa tahapan.Tahapan pertama adalah tahapan analisis. Hasil yang peroleh dari tahapan ini adalah sebagai berikut:

\section{Analisis RPS Mata Kuliah Sejarah Indonesia}


Analisis silabus dilakukan untuk melihat materi yang telah diajarkan telah sesuai dengan standar kompetensi dan kompetensi dasar. Standar kompetensi dari mata kuliah Sejarah Indonesia adalah; (a) mahasiswa mampu memahami konsep Sejarah Indonesia zaman Hindu Budha, (b) mahasiswa mampu membedakan antara Sejarah Indonesia dengan Sejarah Lokal (daerah) dlam pembelajaran sejarah, (c) mahasiswa mampu menjelaskan periodesasi/ pembabakan Sejarah Indonesia berdasarkan bukti-bukti sejarah yang ditemukan., (d) mahasiswa mampu menganalisis semua kejadian-kejadian atau peristiwa-peristiwa sejarah tersebut sebagai bahan acuan atau pedoman untuk masa depan.

Dari hasil tersebut diperoleh bahwa materi yang ada di silabus telah sesuai dengan kompetensi yang harus dicapai oleh mahasiswa. Urutan materi juga telah pas karena materi terdiri dari dua belas bab dan terdiri dari 16 kegiatan belajar.

\section{Hasil Wawancara Dengan Teman Sejawat}

Wawancara dengan teman sejawat bertujuan untuk mengetahui permasalahan yang dihadapi selama proses pembelajaran pada materi bidang kompleks dan fungsi kompleks. Wawancara dilakukan dengan teman sejawat dilakukan pada tanggal 24Agustus2017. Berdasarkan hasil wawancara diperoleh informasi bahwa keseluruhan materi tergolong sulit karena rnahasiswa belum memahami konsep pengajaran Sejarah Indonesia Zaman Hindu - Budha dengan baik, disamping buku teks yang menjadi panduan bagi mahasiswa tidak dipakai oleh mahasiswa sebagaimana mestinya. Pelaksanaan kuliah belum bisa membuat mahasiswa aktif dan mandiri, soal yang ada pada buku teks sudah variatif tetapi mahasiswa kurang mampu menelaah dan mencari penyelesaian dari soal tersebut berdasarkan materi yang telah dipelajari. Mahasiswa tidak mampu memahami dan mempersentasikan kembali laporan bacaan yang telah mereka kerjakan, sehingga pembelajaran Sejarah Indonesia Zaman Hindu - Budhatidak berlangsung dengan lancar, dan hasilnya tidak maksimal.

\section{Angket Kebutuhan Mahasiswa}

Angket kebutuhan mahasiswa bertujuan untuk mengetahui kebutuhan mahasiswa terhadap bahan ajar sehubungan dengan perkuliahan Sejarah Indonesia Zaman Hindu - Budha. Berikut adalah hasil yang diperoleh. 
Tabel 5. Persentase Hasil Angket Kebutuhan Mahasiswa

\begin{tabular}{|c|c|c|c|}
\hline No & Pernyataan & $\begin{array}{c}\text { Jawaban } \\
\text { Mahasiswa }\end{array}$ & $\begin{array}{c}\text { Persenta } \\
\text { se }\end{array}$ \\
\hline 1. & $\begin{array}{l}\text { Menurut pendapat saudara seberapa penting } \\
\text { pengajaran mata kuliah Sejarah Indonesia } \\
\text { Zaman Hindu - Budha? }\end{array}$ & Sangat penting & 100 \\
\hline 2. & $\begin{array}{l}\text { Selama ini dari manakah anda dapatkan } \\
\text { sumber belajar dari mata kuliah Sejarah } \\
\text { Indonesia Zaman Hindu - Budha? }\end{array}$ & Buku-buku Sejarah & 75 \\
\hline 4. & $\begin{array}{l}\text { Bagaimana materi bahan ajar yang anda gunakan } \\
\text { saat ini dalam proses pembelajaran Sejarah } \\
\text { Indonesia Zaman Hindu - Budha? }\end{array}$ & $\begin{array}{c}\text { Sudah lengkap dan } \\
\text { menarik }\end{array}$ & 82 \\
\hline 5. & $\begin{array}{l}\text { Bagaimana bahan ajar mata kuliah Sejarah } \\
\text { Indonesia Zaman Hindu - Budhayang } \\
\text { digunakan,apakah sudah mengunakan metode } \\
\text { pembelajaran? }\end{array}$ & Sudah & 65 \\
\hline 6. & $\begin{array}{l}\text { Apakah anda setuju apabila ada sumber } \\
\text { belajar atau bahan ajar khusus yang } \\
\text { digunakan pada mata kuliah Sejarah Indonesia } \\
\text { Zaman Hindu - Budha? }\end{array}$ & Setuju & 96 \\
\hline 7. & $\begin{array}{l}\text { Apakah anda setuju pada buku ajar Sejarah } \\
\text { Indonesia Zaman Hindu - Budhadigunakan } \\
\text { metodepembelajaran? }\end{array}$ & Setuju & 100 \\
\hline 8. & $\begin{array}{l}\text { Apakah anda menginginkan Buku ajar yang } \\
\text { lengkap memuat evaluasi materi yangsesuai } \\
\text { untuk mata kuliah Sejarah Indonesia Zaman } \\
\text { Hindu - Budha? }\end{array}$ & Setuju & 98 \\
\hline 9. & $\begin{array}{l}\text { Didalam buku ajar perlukah dibuat kata } \\
\text { pengantar dari penulis? }\end{array}$ & Perlu & 88 \\
\hline 10. & $\begin{array}{l}\text { Apakah anda setuju apabila materi yang } \\
\text { dimasukan dalam bahan ajar Sejarah } \\
\text { IndonesiaZaman Hindu - Budhasesuai dengan } \\
\text { Rancangan Pembelajaran Semester (RPS). }\end{array}$ & Setuju & 98 \\
\hline 11. & $\begin{array}{l}\text { Menurut pendapat saudara pada buku ajar } \\
\text { Sejarah Indonesia Zaman Hindu - Budha }\end{array}$ & Perlu & 92 \\
\hline
\end{tabular}

500 | Seminar Nasional Sejarah ke 4 Jurusan Pendidikan Sejarah Universitas Negeri Padang 


\begin{tabular}{|c|c|c|c|}
\hline & perludimasukan contoh soal-soal sejarah? & & \\
\hline 12. & $\begin{array}{l}\text { Menurut anda, judul apa yang sesuai pada } \\
\text { buku ajar Sejarah Indonesia Zaman Hindu - } \\
\text { Budha? }\end{array}$ & $\begin{array}{l}\text { Sejarah Indonesia } \\
\text { Zaman Hindu } \\
\text { Budha }\end{array}$ & 100 \\
\hline 13. & $\begin{array}{l}\text { Menurut pendapat anda sampul seperti apa yang } \\
\text { menarik untuk buku ajar Sejarah Indonesia } \\
\text { Zaman Hindu - Budha tersebut? }\end{array}$ & $\begin{array}{l}\text { Bergambar dan } \\
\text { berwarna }\end{array}$ & 92 \\
\hline 14. & $\begin{array}{l}\text { Menurut anda, dimanakah sebaiknya gambar } \\
\text { dalan buku ajarSejarah Indonesia Zaman Hindu - } \\
\text { Budhatersebut dimuat? }\end{array}$ & Di bawah judul & 75 \\
\hline 15 . & $\begin{array}{l}\text { Menurut anda ukuran huruf yang digunakan } \\
\text { dalam judul buku ajarSejarah Indonesia Zaman } \\
\text { Hindu - Budha seperti apa? }\end{array}$ & Sedang & 68 \\
\hline 16. & $\begin{array}{l}\text { Warna apakah yang sesuai untuk sampul bahan } \\
\text { ajar Sejarah Indonesia Zaman Hindu - Budha? }\end{array}$ & Warna terang & 72 \\
\hline 17. & $\begin{array}{l}\text { Menurut anda berapa jumlah gambar yang } \\
\text { dimasukan dalam bahan ajar Sejarah Indonesia } \\
\text { Zaman Hindu - Budha? }\end{array}$ & Lebih dari satu & 75 \\
\hline 18. & $\begin{array}{l}\text { Setujukah Anda untuk mengisi sampul belakang } \\
\text { buku ajar dibuat Biografi Penulis buku Sejarah } \\
\text { Indonesia Zaman Hindu - Budha? }\end{array}$ & Setuju & 77 \\
\hline 19. & $\begin{array}{l}\text { Jenis huruf (font) seperti apakah yang anda suka } \\
\text { untuk judul bahan ajar Sejarah Indonesia Zaman } \\
\text { Hindu - Budha? }\end{array}$ & Time New Roman & 92 \\
\hline 20. & $\begin{array}{l}\text { Ukuran buku seperti apakah yang sesuai untuk } \\
\text { bahan ajar Sejarah Indonesia Zaman Hindu - } \\
\text { Budha? }\end{array}$ & Ukuran kecil A4 & 88 \\
\hline 21. & $\begin{array}{l}\text { Perlukah disertakan daftar isi dalam bahan ajar } \\
\text { Sejarah Indonesia Zaman Hindu - Budha? }\end{array}$ & Tidak perlu & 100 \\
\hline 22. & $\begin{array}{l}\text { Perlukah disertakan glosarium dalam buku ajar } \\
\text { Sejarah Indonesia Zaman Hindu - Budha? }\end{array}$ & Perlu & 98 \\
\hline 23. & $\begin{array}{l}\text { Perlukah disertakan daftar pustaka dalam buku } \\
\text { ajarSejarah Indonesia Zaman Hindu - Budha? }\end{array}$ & Perlu & 100 \\
\hline 24. & Menurut Saudara dimanakah dicantumkan nomor & Di bawah & 98 \\
\hline
\end{tabular}

501 | Seminar Nasional Sejarah ke 4 Jurusan Pendidikan Sejarah Universitas Negeri Padang 


\begin{tabular}{|c|l|l|c|}
\hline 25. & $\begin{array}{l}\text { Dalaman buku ajar nantinya } \\
\text { - Budhatersebut bentuk soal seperti apa yang } \\
\text { perlu dimasukan? }\end{array}$ & 62 \\
\hline 26. & $\begin{array}{l}\text { Bagaimana bahasa yang digunakan dalam } \\
\text { buku ajar Sejarah Indonesia Zaman Hindu - } \\
\text { Budha? }\end{array}$ & Mudah dipahami & 75 \\
\hline 27. & $\begin{array}{l}\text { Apakah Harapan anda terhadap bahan ajar } \\
\text { Sejarah Indonesia Zaman Hindu - Budha } \\
\text { yangdikemas dalam buku? }\end{array}$ & $\begin{array}{l}\text { Agar bahan ajar } \\
\text { bisa dimanfaatkan }\end{array}$ & 82 \\
\hline
\end{tabular}

Dari tabel di atas diperoleh kesimpulan bahwa mahasiswa $100 \%$ setuju jika ada pengajaran mata kuliah Sejarah Indonesia Zaman Hindu - Budha. Mahasiswa 100\% setuju jika dalam penyajian buku ajar digunakan metode pembelajaran. Mahasiswa 94\% setuju pada buku ajar Sejarah Indonesia Zaman Hindu - Budhaperlu dimasukan contoh-contoh soal. Mahasiswa 98\% setuju bahwa perlu disertakan glosarium dalam buku ajar.. Mahasiswa $82 \%$ mengharapkan agar bahan ajar Sejarah Indonesia Zaman Hindu - Budhadikemas dalam buku.

\section{Hasil Analisis Buku Teks}

Buku teks yang dirancang dan dikembangkan bertujuan untuk membantu mahasiswa memahami materi pada perkuliahan Sejarah Indonesia Zaman Hindu - Budha. Buku teks yang ada selama ini tidak digunakan secara maksimal oleh mahasiswa dan hanya menggunakan catatan yangdiberikan oleh dosen tanpa mernbuka dan mempelajari dari buku teks tersebut. Selain buku teks pada mata kuliah Penilaian hasil Belajar belum ada buku ajar yang mampu membuat mahasiswa berpartisipasi secara aktif, sehingga mahasiswa dapat memahami materi yang telah dipelajari.

\section{MereviewRPS dan Buku Ajar berdasarkan Pendekatan Contextual Teaching and Learning}

RPS dan buku ajar yang digunakan oleh mahasiswa selama ini kurang lengkap, karena masih banyak materi penting yang berkaitan dengan Sejarah Indonesia Zaman Hindu - Budha belum dimasukan dalam RPS dan buku ajar. Disamping itu masih ada perbedaan antara materi yang ada dibuku ajar berbeda dengan yang di RPS. Sehingga Kompetensi Dasar yang diharapkan 502 | Seminar Nasional Sejarah ke 4 Jurusan Pendidikan Sejarah Universitas Negeri Padang 
belum tercapai dengan maksimal. Dari segi keindahan dan daya tarik buku belum terlihat karena covernya kurang menarik untuk dilihat dan dibaca.

Berdasarkan analisis di atas, maka dirancanglah RPS dan buku ajar berdasarkan pendekatan CTL yang memiliki kompetensi dasar yang sesuai dengan kurikulum Sejarah Indonesia Zaman Hindu - Budhadan diharapkan buku ini dapat dipergunakan oleh mahasiswa dan dosen pada mata kuliah Sejarah Indonesia Zaman Hindu - Budha. Buku ajar ini berisi tentang materi perkuliahan Sejarah Indonesia Zaman Hindu - Budhasecara lengkap dan efisien serta dengan membaca buku ajar ini mahasiswa mampu mengkonstruksi pengetahuannya karena materi yang dibuat telah dirancang dan disusun dengan lengkap secara gradasi. Dalam buku ajar ini juga dibuat soal-soal latihan yang terstruktur untuk melatih dan meningkatkan kemampuan serta pemahaman siswa dalam menyelesaikan soal yang diberikan. Dalam RPS dan Buku ajar yang dibuat berdasarkan pendekatan CTL ini berisi standar kompetensi yang akan dicapai, seperti: kompetensi dasar, tujuan pembelajaran, materi lengkap, ringkasan materi, evaluasi dan daftar pustaka.

\section{Data Tahap Desain (Design)}

Tahap desain adalah tahap rancangan awal untuk menyusun dan mengembangan perangkat pembelajaran Sejarah Indonesia Zaman Hindu - Budhadengan menggunakan pendekatan CTL.

Pada tahap ini di desain berbagai perangkat pembelajaran Sejarah Indonesia Zaman Hindu Budhayang meliputi: pengembangan RPS, pembuatan Satuan Acara Perkuliahan (SAP), penulisan buku ajar yang kesemuanya berdasarkan pendekatan CTL. Setelah semuanya di desain, maka dilanjutkan dengan pembuatan RPS, SAP dan buku ajar berdasarkan rancangan yang sudah ada.

\section{a. Pembuatan Draf Rancangan RPS, SAP dan Buku Ajar}

\section{i. Draf Rancangan RPS}

Draf RPS adalah Rancangan Pembelajaran Semester yang dibuat oleh dosen pengampu mata kuliah pada awal semester setiap mata kuliah yang mereka ampu namun masih dalam bentuk draf. Draf RPS ini memuat identitas mata kuliah, deskripsi mata kuliah, capaian pembelajaran, kompetensi (umum dan khusus), jumlah jam (alokasi waktu). Garis Besar Rancangan Perkuliahan, tugas dan latihan, penilaian, tata tertib perkuliahan serta referensi. 


\section{ii.Draf Rancangan SAP}

Draf SAP adalah Satuan Acara Perkuliahan yang dibuat oleh dosen pengampu mata kuliah pada awal semester setiap mata kuliah yang mereka ampu namun masih dalam bentuk draf. Draf SAP memuat identitas standar, standar kompetensi, kompetensi dasar, indikator, tujuan, model, metode pembelajaran, kegiatan pembelajaran (langkah-langkah pembelajaran Sejarah Indonesia Zaman Hindu - Budha), evaluasi/ penilaian dan referensi. Draf Satuan Acara Perkuliahan (SAP) dibuat berdasarkan draf RPS yang telah dirancang oleh dosen pengampu mata kuliah yang bersangkutan. Draf SAP dibuat berdasarkan masing-masing pertemuan perkuliahan untuk setiap kali masuk.

\section{Iii. Draf Rancangan Buku Ajar}

Draf buku ajar adalah buku yang dibuat berdasarkan draf RPS dan SAP yang telah dirancang dan dibuat oleh dosen pengampu mata kuliah bersangkutan dengan menggunakan pendekatan CTL. Draf Buku ajar ini memuat tentang model cover buku ajar, daftar isi, materi kegiatan belajar, latihan, tes/evaluasi, dan daftar pustaka. Penggunaan buku ajar ini akan memudahkan dosen dan mahasiswa dalam pembelajaran Sejarah Indonesia Zaman Hindu Budha. Dengan pendekatan CTL mahasiswa dapat mengkonstruksi pengetahuan dan pengalaman mereka sendiri dengan cara terlibat aktif dalam proses perkuliahan berdasarkan materi kegiatan pembelajaran.

\section{b. Pembuatan RPS, SAP, dan Buku Ajar i.Rancangan RPS}

RPS adalah Rancangan Pembelajaran Semester yang dibuat oleh dosen pengampu mata kuliah pada awal semester setiap mata kuliah yang mereka ampu namun masih dalam bentuk. RPS ini memuat identitas mata kuliah, deskripsi mata kuliah, capaian pembelajaran, kompetensi (umum dan khusus), jumlah jam (alokasi waktu). Garis Besar Rancangan Perkuliahan, Tugas dan latihan, penilaian, tata tertib perkuliahan serta referensi.

\section{b.Rancangan SAP}

SAP adalah Satuan Acara Perkuliahan yang dibuat oleh dosen pengampu mata kuliah pada awal semester setiap mata kuliah yang mereka ampu namun masih dalam bentuk SAP memuat 
identitas standar, standar kompetensi, kompetensi dasar, indikator, tujuan, model, metode pembelajaran, kegiatan pembelajaran (langkah-langkah pembelajaran Sejarah Indonesia Zaman Hindu - Budha, evaluasi/ penilaian dan referensi. Satuan Acara Perkuliahan (SAP) dibuat berdasarkan RPS yang telah dirancang oleh dosen pengampu mata kuliah yang bersangkutan. SAP dibuat berdasarkan masing-masing pertemuan perkuliahan untuk setiap kali masuk.

Evaluasi yang digunakan pada pembuatan SAP ini adalah evaluasi diri.Desain SAP dievaluasi sendiri oleh peneliti menggunakan pedoman evaluasi diri kemudian dianalisis dan direvisi berdasarkan hasil evaluasi diri tersebut.Data hasil tahap pembuatan SAP disajikan berdasarkan aspek-aspek kemudahan dalam penggunaan, dan sapek kesesuaian dengan waktu.

\section{Tabel 6. Aspek Penilaian SAP}

\begin{tabular}{|c|c|}
\hline No & Aspek yang Dinilai \\
\hline A. & Aspek Kelayakan Isi \\
\hline 1 & Deskripsi mata kuliah sesuai dengan capaianpembelajaran \\
\hline 2 & $\begin{array}{l}\text { Indikator yang dirumuskan dalam SAP telahmemenuhi hal-hal yang dituntut dalam } \\
\text { capaianpembelajaran }\end{array}$ \\
\hline 3 & $\begin{array}{l}\text { Tujuan pembelajaran yang dirumuskan dalam SAPtelah sesuai dengan capaian } \\
\text { pembelajaran }\end{array}$ \\
\hline 4 & Sistem penilaian sesuai dengan capaian pemelajaran \\
\hline 5 & Materi yang ada di dalam SAP sesuai dengancapaian pembelajaran \\
\hline 6 & Metode dan strategi pembelajaran tergambar jelas di dalam SAP \\
\hline 7 & Penilaian tergambar jelas di dalam SAP \\
\hline 8 & Alokasi waktu dijelaskan secara jelas \\
\hline 9 & Referensi materi pembelajaran tergambar di dalam SAP \\
\hline B & Aspek Kelayakan Bahasa \\
\hline 1 & $\begin{array}{l}\text { Bahasa yang digunakan dalam SAP sesuai denganEjaan yang Disempurnakan } \\
\text { (EYD) }\end{array}$ \\
\hline 2 & Kata-kata dan istilah yang digunakan dalam silabusbaku dan SAP (mudah dipahami) \\
\hline 3 & Kalimat dalam SAP sesuai dengan kaidah tatakalimat bahasa Indonesia \\
\hline 4 & Gaya penyampaian dalam SAP komunikatif \\
\hline 5 & $\begin{array}{l}\text { Bahasa yang digunakandalam SAP membangkitkanrasa senang ketika peserta didik } \\
\text { membacanya }\end{array}$ \\
\hline 6 & $\begin{array}{l}\text { Bahasa yang digunakan dalam SAP sederhana dansesuai dengan tingkat } \\
\text { perkembangan peserta didik }\end{array}$ \\
\hline
\end{tabular}




\begin{tabular}{|l|l|}
\hline C & Aspek Kelayakan Penyajian \\
\hline 1 & Judul materi/subbab dalam SAP singkat dan jelas \\
\hline 2 & Capaian pembelajaran pada perangkat pembelajarandinyatakan dengan jelas \\
\hline 3 & Deskripsi mata kuliah dalam SAP mudah dipahamioleh peserta didik \\
\hline 4 & Sistem penilaian dalam silabus mencerminkancapaian pembelajaran \\
\hline D & Aspek Kelayakan Kegrafikan \\
\hline 1 & Bentuk dan ukuran huruf SAP sesuai dengantingkat perkembangan peserta didik \\
\hline 2 & Desain tampilan SAP sederhana dan menarik bagipeserta didik \\
\hline 3 & Sampul SAP menarik dan mewakili materipembelajaran \\
\hline
\end{tabular}

Dalam membuat SAP perlu dipertimbangkan keterkaitan antara pokok bahasan dengan sub pokok bahasan agar materi yang diajarkan nantinya saling berkesinambungan. Pada evaluasi yang dilakukan oleh validator, ternyata SAP yang dibuat oleh peneliti tidak banyak dilakukan perubahan. Perubahan yang ada adalah pemindahan waktu pertemuan agar dimasukan kedalam tabel SAP. Sedangkan konten isi dari SAP sendiri tidak mengalami perubahan sedikitpun

\section{Simpulan.}

Berdasarkan penelitian yang telah berjalan selama 4 bulan dapat disimpulkan bahwa: Mahasiswa 100\% setuju jika ada pengajaran mata kuliah Sejarah Indonesia Zaman Hindu - Budha. Mahasiswa $100 \%$ setuju jika dalam penyajian buku ajar digunakan metode pembelajaran. Mahasiswa 94\% setuju pada buku ajar Sejarah Indonesia Zaman Hindu - Budha perlu dimasukan contoh-contoh soal. Mahasiswa 98\% setuju bahwa perlu disertakan glosarium dalam buku ajar.Mahasiswa $82 \%$ berharap agar bahan ajar sejarah dikemas dalam bentuk buku ajar. Mahasiswa 92\% setuju agar dalam menulis buku Sejarah Indonesia Zaman Hindu Budhamenggunakan huruf/ jenis huruf (font) time new roman. Mahasiswa 100\% setuju agar dalam menulis buku Sejarah Indonesia Zaman Hindu - Budha dibuatkan daftar pustakanya dan Mahasiswa $100 \%$ setuju agar buku yang akan ditulis itu diberi judul: Sejarah Indonesia Zaman Hindu - Budha. Berdasarkan capaian penelitian ini disarankan bahwa mahasiswa Tadris IPS Konsentrasi Sejarah perlu memiliki Buku Ajar sehingga pembelajarannya dapat terbantu. Kemudian untukmendapatkan buku ajar yang komplit perludilakukan kajian yang lebih mendalam untuk mengembangkan Buku Ajar kearah kesempurnaan supaya dapat dijasikan sebagai pedoman dalan pengajaran nantinya. Amin. 


\section{DAFTAR PUSTAKA}

Adrian Lapian. 2008. Pelayaran dan Perniagaan Nusantara Abad Ke-16 dan 17. Depok: Komunitas Bambu.

Agus Aris Munandar. 2012. Indonesia dalam Arus Sejarah. Jakarta: PT Ichtiar Baru van Hoeve.

Coedès, George. 1996. The Indianized States of Southeast Asia. University of Hawai Press.

Krisna Bayu Adji. 2014. Sejarah Runtuhnya Kerajaan-kerajaan Di Nusantara. Yogyakarta: Araska.

Marwati Dioened Poesponegoro, dan Nugroho Notosusanto. 1993. Seiarah Nasional Indonesia: Zaman Kuno, Jakarta; PT Balai Pustaka,

Milet, Didier. 2003. Indonesian Heritage Series Ancient History, Singapore: Press Archipelago.

Nastiti Poesponegoro. 2007. Prasasti Majapahit. Jakarta: Direktorat Jenderal Sejarah dan Purbakala.

Refinaldi.2011. Sejarah Indonesia Zaman Hindu-Budha. Padang: Hayfa Press.

Sartono Kartodirjo. 1988. Pengantar Sejarah Indonesia. Jakarta: PT. Gramedia. 